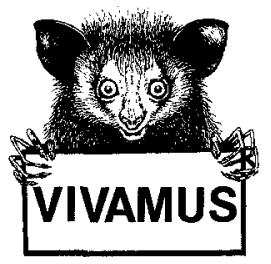

\title{
A Comparative Perspective on the Evolution of Tamarin and Marmoset Social Systems
}

\author{
Anne Wilson Goldizen ${ }^{1,2}$ \\ Received July 6, 1988; revised April 11, 1989
}

Tamarins and marmosets (callitrichids) present an unusual opportunity for study of the determinants of primate social systems, because both the mating and infant care patterns of callitrichids are variable, even within individual populations. In this paper, I briefly describe three characteristics of callitrichid social systems that distinguish them from most other primates: extensive male parental care, helping by nonreproductive individuals, and variable mating patterns. I then discuss the evolution of these characteristics and of the frequent twinning exhibited by callitrichids. I suggest that an ancestor of modern callitrichids gave birth to a single offspring at a time, mated monogamous$l y$, and had significant paternal care. The idea that males of this ancestral form must have provided paternal care, even though only single infants were born, derives from a comparison of litter/mother weight ratios in modern primate species. Twinning perhaps then evolved because of a combination of dwarfing in the callitrichid lineage, leading to higher litter/mother weight ratios, and a high infant mortality rate, and because the extensive paternal care already present facilitated the raising of twins. I propose that the helping behavior of older offspring may have coevolved with twinning, because helpers would have increased the chances of survival of twins, and the presence of twins would have increased the benefits of helping. Finally, the high costs of raising twins and the variability of group compositions, especially the fact that some groups would not have had older offspring to serve as helpers, may have selected for facultative polyandry in saddle-back tamarins (Saguinus fuscicollis) and perhaps in other callitrichid species. Both help-

\footnotetext{
${ }^{1}$ Department of Anthropology, 1054 LSA Building, University of Michigan, Ann Arbor, Michigan, 48109.

${ }^{2}$ Present address: Zoology Department, University of Tasmania, Hobart, G. P. O. Box 252C, Tasmania 7001, Australia.
} 
ing and cooperative polyandry have been extensively studied in bird species, and I apply some of the conclusions of these studies to the discussion of the evolution of callitrichid social systems.

KEY WORDS: callitrichids; polyandry; helping; twinning; paternal care.

\section{INTRODUCTION}

It is generally accepted that most intraspecific variation in social systems is neither random nor maladaptive but is, in fact, adaptive. Indeed, the possible adaptive significance of different mating patterns and social systems is probably best studied by intraspecific comparisons within species that exhibit a variety of reproductive strategies. In such comparisons, phylogenetic histories are less likely to complicate interpretations, and many demographic and ecological factors are controlled for.

Tamarins and marmosets (Callitrichidae) are particularly interesting for intraspecific comparisons of reproductive strategies because they have unusually variable and flexible patterns of infant care, and in some species, of mating (reviewed by Sussman and Kinzey, 1984; Goldizen, 1987a, 1988; Snowdon and Soini, in press). The social systems of callitrichids differ in three major ways from those of most or all other primate species. (1) Breeding males provide at least as much infant care, and perhaps even more, than do breeding females. (2) Nonbreeding individuals, both before and after the age of potential sexual maturity, provide substantial help with the rearing of their infant siblings. (3) Members of some callitrichid species may only mate monogamously; but, saddle-back tamarins (and possibly other species) exhibit the following mating patterns: monogamy, cooperative polyandry, and polygyny and/or polygynandry.

Unfortunately, studies of reproductive strategies in wild primates are hampered by many difficult logistical problems. (1) Most primates live at quite low population densities, often in dense forest, so that many field studies only involve between one and three social groups. (2) Primates are often difficult to habituate and to mark individually for long-term recognition. (3) For methodological, ethical, or political reasons, it is usually not possible to move individual primates around or otherwise to alter group compositions in order to test hypotheses about the causes of specific strategies or social systems. (4) It is often either not practical or illegal to trap wild primates for collection of tissue samples to test paternity or genetic relatedness.

Many of these problems are absent in studies of other taxa, such as birds, amphibians, and insects. While field studies of primate social systems and alternative reproductive strategies are indispensible, our understanding 
of these apsects of primate behavior could be increased greatly by a deeper understanding of the causes of similar behaviors in animals of other taxa.

The subject of this paper, the social systems of callitrichids, illustrates the usefulness of comparing similar behaviors in different taxa. Logistical problems in studying wild callitrichids are such that, despite more than 15 to 20 total years of fieldwork, there are still very few data on the behavior of wild individuals. On the other hand, the aspects of callitrichid social systems that are of most interest to primatologists (extensive male parental care, nonreproductive helpers, monogamy, and polyandry) have been well studied in other taxa, especially birds.

In this paper, I first summarize what is known about the social systems of tamarins and marmosets. Then, I discuss the evolution of callitrichid social systems, drawing heavily on ideas derived from studies of other taxa.

\section{Brief Summary of Callitrichid Social Systems}

The Callitrichidae consist of approximately 15 species in 4 genera, 2 of marmosets (Cebuella and Callithrix) and 2 of tamarins (Saguinus and Leontopithecus) (Hershkovitz, 1977). Callitrichids are the only anthropoid primates which regularly twin (in captivity about $80 \%$ of births consist of twins, Gengozian et al., 1978).

\section{Parental Care}

Tamarins and marmosets provide three forms of infant care that are energetically costly - lactation, infant-carrying, and the provision of insects and fruits to infants and juveniles. Infants are weaned from both milk and carrying at around the age of three months. During the first three months, breeding females have to increase their food intake by 50 to $100 \%$ in order to produce sufficient milk for twin infants (Kirkwood and Underwood, 1984, for captive cotton-top tamarins, Saguinus oedipus; Goldizen, 1987b, for wild saddle-back tamarins, Saguinus fuscicollis). Meanwhile, infants are carried wherever the group goes; they are occasionally "parked," but only while the other group members feed nearby. Because the daily travel distances of callitrichids are often long (averaging one to two $\mathrm{km}$ for many species; reviewed by Sussman and Kinzey, 1984; Goldizen, 1987a), infant-carrying must also be an energetically costly form of care.

Many studies of callitrichids have shown that adult males do as much and usually more infant-carrying than breeding females do (in the wild: Terborgh and Goldizen, 1985; Goldizen, 1987b, for S. fuscicollis; Rylands, 1985, for tassel-ear marmosets, Callithrix humeralifer; Garber, 1986, for mous- 
tached tamarins, S. mystax; in captivity: Epple, 1975; Vogt et al., 1978; Cebul and Epple, 1984, for S. fuscicollis; Box, 1975; Ingram, 1977; Tardif et al., 1986, for common marmosets, Callithrix jacchus; Hoage, 1978, for golden lion tamarins, Leontopithecus rosalia; Tardif et al., 1986, for S. oedipus). Both males and females also allow infants and juveniles to take fruits and prey items (insects and occasional small vertebrates) from them (in the wild: Terborgh and Goldizen, 1985; Goldizen, 1987b, for S. fuscicollis; in captivity: Brown and Mack, 1978, for L. rosalia).

\section{Helpers}

In all of the callitrichid species in which infant care has been studied, offspring that are still in their natal groups usually help to carry their infant siblings (in the wild: Terborgh and Goldizen, 1985; Goldizen, 1987b, for $S$. fuscicollis; Rylands, 1985, for C . humeralifer; in captivity: Epple, 1975; Vogt et al., 1978; Cebul and Epple, 1984, for S. fuscicollis; Box, 1975; Ingram, 1977; Tardif et al., 1986, for C. jacchus; Hoage, 1978, for L. rosalia; Tardif et al., 1986, for $S$. oedipus). Older offspring also provide food to younger siblings (Goldizen, 1987b, for S. fuscicollis).

The actual amounts of infant-carrying done by individuals of different age-sex classes are variable. However, some possible trends are beginning to emerge. First, the amount of infant-carrying done by older offspring seems to increase with age (in the wild: Rylands, 1985, for C. humeralifer; Goldizen, 1987b, for S. fuscicollis; in captivity: Vogt et al., 1978, for S. fuscicollis; Tardif et al., 1986, for C. jacchus). In wild $S$. fuscicollis, only some one-year old or younger juveniles carry their infant siblings; individuals of this age perhaps contribute substantially to carrying only when their group does not have enough older carriers (Terborgh and Goldizen, 1985; Goldizen, 1987b). Secondly, there may be species differences in how soon after the birth of infants individuals of different age-sex classes begin to carry the infants. For instance, in captive $L$. rosalia, mothers are usually the sole carriers during the first week of infants' lives (Hoage, 1978). In wild S. fuscicollis and captive $C$. jacchus, adult males and some older offspring carry infants as early as the first or second day after birth (Goldizen, unpubl. observations; Box, 1975). Thirdly, the amount of care provided by parents may be affected by the number of helpers they have. For example, McGrew (1988) showed that, in captive $S$. oedipus, the amount of parental care (including infantcarrying) performed by mothers and fathers tended to decline with increasing numbers of helpers. 


\section{Mating Patterns}

Until recently, it was thought that callitrichids always mated monogamously (e.g., Eisenberg et al., 1972; Kleiman, 1977; Leutenegger, 1980). This conclusion was supported by the following observations. (1) Groups consisting of mated pairs and their offspring were the most stable type of group in captivity. (2) Groups observed in the wild never had more than one breeding female simultaneously (Dawson, 1978; Neyman, 1978, for S. oedipus; Izawa, 1978, for the black-mantle tamarin, S. nigricollis; Hubrecht, 1984, for C. jacchus). (3) In captivity both adult males and females were often quite hostile to adults of the same sex (other than their grown offspring) (Wolfe et al., 1975; Epple, 1978). However, aggression towards unrelated adults is not universal (Epple, 1972, for S. fuscicollis; Coates and Poole, 1983, for red-chested tamarins, $S$. labiatus).

Studies of the mating patterns of wild callitrichids have progressed slowly because most of them did not involve animals that were both habituated and individually marked and because, even with habituated animals, copulations of tamarins and marmosets are difficult to see. They last only a few seconds and do not occur in predictable situations.

Only two published studies have yielded data on both parental care and mating patterns. In the S. fuscicollis population living in Peru's Manu National Park, some groups consisted of monogamous pairs with offspring, while others were polyandrously mated individuals (one female with more than one male) with or without offspring. In addition, one group appeared to be polygynous (two females were pregnant at the same time) and another was either polygynous or polygynandrous (more than one male mated to more than one female) (Terborgh and Goldizen, 1985; Goldizen, 1987b). The form of polyandry exhibited by these tamarins, in which the female has a single set of offspring at a time that are cared for by all of the adults, is called cooperative polyandry (Faaborg and Patterson, 1981). In the best-studied polyandrous group, the two males mated with equal frequency, and did equal amounts of infant-carrying (Goldizen, 1987b). Accurate data on the frequency of these different mating patterns in the Manu population are not yet available, but preliminary observations suggest that polyandry may be the most common, followed by monogamy, with other patterns quite rare. In Ryland's study group of $C$. humeralifer on the Rio Aripuana in Brazil, all three adult males mated with the same female, and all carried infants, though one male did much less infant-carrying than the other two did (Rylands, 1985).

Cooperative polyandry is also suspected to occur (based on group compositions) in S. mystax (Garber et al., 1984) and emperor tamarins (S. im- 
perator) (Goldizen, unpubl. data), and in $L$. rosalia (based on observations of two males mating with the same female; Dietz and Kleiman, 1986). Observations of matings among wild individuals have been published for only two other species. Hubrecht (1985) observed four matings between a young female $C$. jacchus of one group and one or more males of a neighboring group. Such intergroup matings have not been recorded for other callitrichid species, and do not yet have a clear explanation. Soini (1987) described a six-day postpartum estrous period in a group of wild pygmy marmosets (Cebuella pygmaea) consisting of two adult males, one adult female, and offspring. During this period both males attempted to mate with the female, but the alpha male was more aggressive and was the only one to mate successfully with the female, suggesting that this group was not polyandrous in the way that some groups of $S$. fuscicollis and the group of $C$. humeralifer described before were. Much more data are needed on the mating patterns of wild callitrichids before we can know whether all species are facultatively polyandrous, or whether some are indeed obligately monogamous.

\section{EVOLUTION OF CALLITRICHID SOCIAL SYSTEMS}

In this section I will discuss the following aspects of tamarin and marmoset physiology and social systems in the order in which I think that they are most likely to have evolved: male parental care, helping and twinning, and then variable mating patterns (Figure 1). I assume that these are most likely to have evolved after monogamy in callitrichid ancestors, but I will not discuss the evolution of monogamy here. It is possible, but seems less likely, that monogamy could have evolved in a polygynous ancestor that already exhibited significant paternal care.

\section{Male Parental Care}

It is believed by some researchers that callitrichid ancestors were larger than present-day forms and, therefore, that the evolution of callitrichids has involved dwarfing (Leutenegger, 1973, 1979, 1980; Ford, 1980). However, Sussman and Kinzey (1984) are skeptical about the dwarfism hypothesis; they suggest instead that all the features that Leutenegger and Ford consider to be evidence of dwarfing could have other explanations. A decrease in body size could have been selected for because it allowed the callitrichid ancestors to shift to foods, such as insects, gum and nectar, that were not heavily used by competing primate species. Before dwarfing occurred, callitrichid ances- 


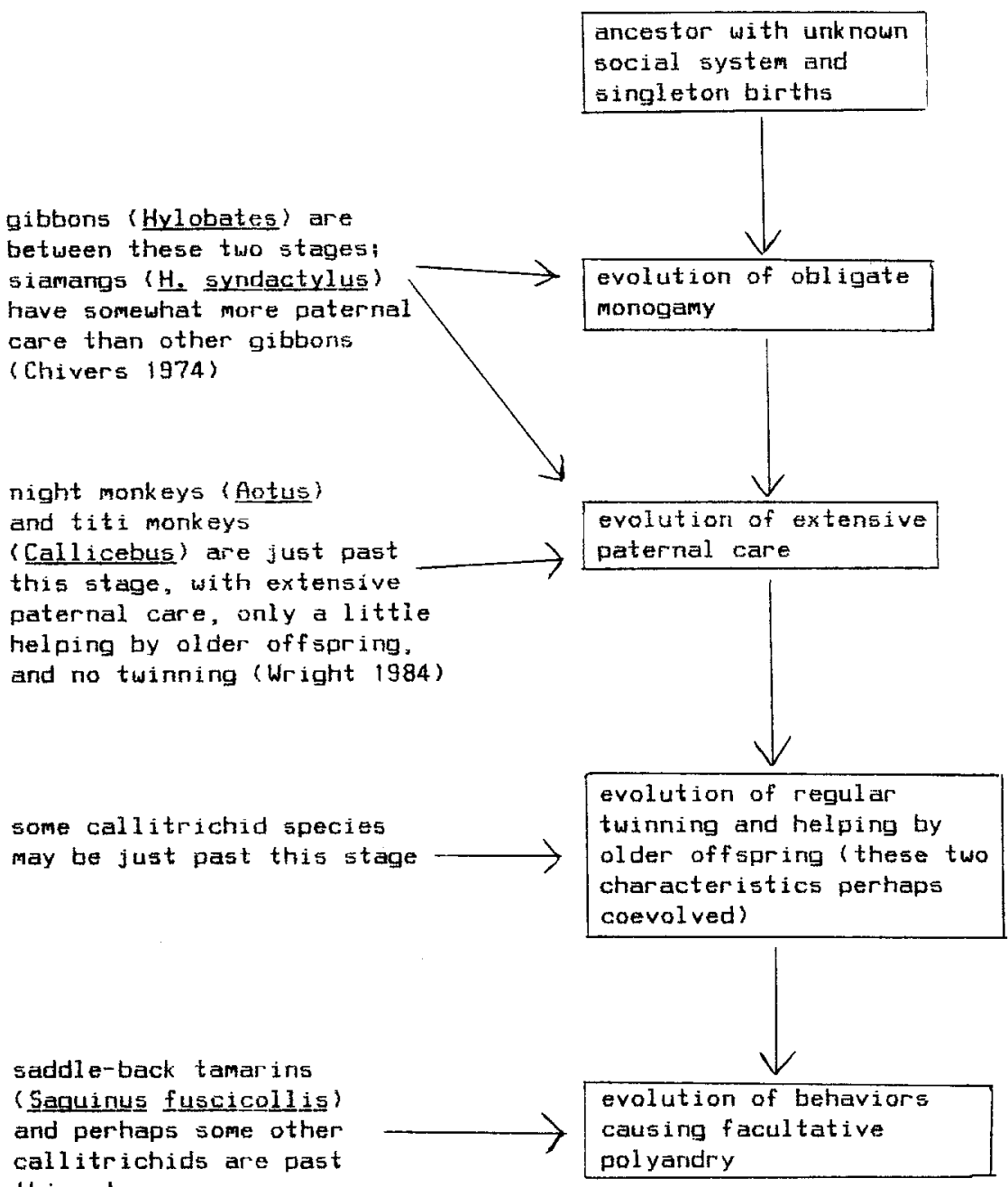

this stage

Fig. 1. Hypothesized chain of events in the evolution of the social systems of callitrichids and other monogamous primate species. This does not imply that the other monogamous species noted on this figure will necessarily continue through this entire evolutionary sequence.

tors may have been about $1 \mathrm{~kg}$, the size of the smaller modern species of Cebidae. It is also believed that, like cebids, ancestral callitrichids gave birth to singletons (Leutenegger, 1973). Modern callitrichids show the tell-tale signs of this ancestry in their unicornate uterus and single pair of nipples.

Since the mating patterns of modern callitrichids are either monogamous or an extension of monogamy (cooperative polyandry can be viewed 
as an outgrowth of monogamy because it involves more than one male being paired to a single female), it is probably reasonable to assume that the most recent pre-dwarfing ancestor of callitrichids was also monogamous, and that this species exhibited fairly extensive male parental care. This last conclusion derives from a comparison of maternal-fetal weight ratios in modern primates.

In modern callitrichids litter birth weight/mother weight ratios range from 0.14 to 0.23 (Table I). Kleiman (1977) suggested that, when a primate mother's litter grows to more than 20 to $25 \%$ of her weight, the mother is no longer able to carry the young without help. In fact, among primates in general there seems to be a threshold at a litter birth weight/mother weight ratio of approximately 0.10 above which mothers might not be capable of carrying their infant(s) constantly throughout their period of dependency, as do most female primates. Leutenegger (1973) and Kleiman (1977) list only a few primates other than callitrichids that have ratios above 0.10 : the western gray mouse lemur (Microcebus murinus), the lesser and dwarf bushbabies (Galago senegalensis and G. demidovii), the Philippine tarsier (Tarsius syrichta), the common squirrel monkey (Saimiri sciureus), and the night monkey (Aotus trivirgatus).

In none of these species, with the possible exception of Saimiri, do mothers carry their infants constantly (Table I). M. murinus, two Galago species, and $T$. syrichta all leave their newborns in tree holes or nests, although it is not clear how long the infants remain in these nests (Richard, 1987; Bearder, 1987). Aotus are monogamous, and males do most of the infantcarrying (Wright, 1984). Female S. sciureus are often helped with infantcarrying by other females, sometimes extensively (Carol Mitchell, pers. comm.). However, some female $S$. sciureus seem to carry their young without help, but the fact that most females only have infants every other year, even though infant-carrying only lasts about four months, suggests that infant care is very draining energetically to females (C. Mitchell, pers. comm.).

Because the callitrichid ancestor had single young, it perhaps had litter/ mother weight ratios lower than modern callitrichids do, but these were nonetheless probably over 0.10 . Together with the likelihood that this ancestral species was monogamous, this suggests that the ancestor exhibited significant paternal care.

\section{Twinning and Helping}

It is not clear in what order twinning and the helping behavior of older offspring are likely to have evolved. In fact, it is perhaps most likely that the two coevolved, with an increased frequency of twinning selecting for helping behavior by older offspring and, at the same time, an increased frequency of helping making even more frequent twinning possible. 
Table I. Litter/Mother Weight Ratios and Type of Infant Transport for a Sample of Primate Species $^{a}$

\begin{tabular}{|c|c|c|c|}
\hline Species & $\begin{array}{c}\text { Litter/mother } \\
\text { weight ratio }\end{array}$ & $\begin{array}{c}\text { Type of infant } \\
\text { transport }\end{array}$ & Reference \\
\hline \multicolumn{4}{|l|}{ Prosimians: } \\
\hline $\begin{array}{l}\text { ring-tailed lemur } \\
\text { (Lemur catta) }\end{array}$ & 0.04 & mother? & \\
\hline $\begin{array}{l}\text { potto } \\
\text { (Perodicticus potto) }\end{array}$ & 0.04 & mother & in Bearder, 1987 \\
\hline $\begin{array}{l}\text { western gray } \\
\text { mouse lemur }\end{array}$ & 0.14 & $\begin{array}{l}\text { mother, } \\
\text { also stored }\end{array}$ & in Richard, 1987 \\
\hline $\begin{array}{l}\text { (Microcebus murinus) } \\
\text { lesser bushbaby } \\
\text { (Galago senegalensis) }\end{array}$ & 0.10 & $\begin{array}{l}\text { in nests } \\
\text { mother, } \\
\text { also stored } \\
\text { in nests }\end{array}$ & in Bearder, 1987 \\
\hline $\begin{array}{l}\text { dwarf bushbaby } \\
\text { (Galago demidovii) }\end{array}$ & 0.13 & $\begin{array}{l}\text { mother, } \\
\text { also stored } \\
\text { in nests }\end{array}$ & in Bearder, 1987 \\
\hline $\begin{array}{l}\text { Philippine tarsier } \\
\text { (Tarsius syrichta) }\end{array}$ & 0.22 & $\begin{array}{l}\text { mother, } \\
\text { also stored } \\
\text { in nests }\end{array}$ & in Bearder, 1987 \\
\hline
\end{tabular}

Callitrichids:

common marmoset

$0.21-0.27$

$0.22-0.23$

pygmy marmoset

(Cebuella pygmaea)

cotton-top tamarin

(Saguinus oedipus)

golden lion tamarin

(Leontopithecus rosalia)

Cebids:

night monkey

(Aotus trivirgatus)

spider monkey

(Ateles fusciceps

and $A$. geoffroyi)

common squirrel monkey

(Saimiri sciureus)

\subsection{9 \\ $0.14-0.18$}

$0.12-0.14$

$0.06-0.07$

$0.12-0.16$

Cercopithecids:

rhesus monkey

(Macaca mulatta)

gelada baboon

(Theropithecus gelada)

$$
\begin{gathered}
0.03-0.14 \\
0.07 \text { (different study) } \\
0.05
\end{gathered}
$$

\begin{tabular}{|c|c|c|c|}
\hline $\begin{array}{l}\text { siamang } \\
\text { (Symphalangus }\end{array}$ & $0.05-0.06$ & $\begin{array}{l}\text { mother and } \\
\text { father }\end{array}$ & Chivers, 1974 \\
\hline syndactylus) & & & \\
\hline $\begin{array}{l}\text { orangutan } \\
\text { (Pongo pygmaeus) }\end{array}$ & 0.04 & mother & $\begin{array}{l}\text { in Rodman and } \\
\text { Mitani, } 1987\end{array}$ \\
\hline $\begin{array}{l}\text { gorilla } \\
\text { (Gorilla gorilla) }\end{array}$ & $0.02-0.04$ & mother & Fossey, 1983 \\
\hline $\begin{array}{l}\text { common chimpanzee } \\
\text { (Pan troglodytes) }\end{array}$ & 0.04 & $\begin{array}{l}\text { primarily } \\
\text { mother }\end{array}$ & Nishida, 1983 \\
\hline
\end{tabular}

Apes:

parents and Box, 1975

older siblings

parents and

older siblings?

parents and

older siblings

parents and

older siblings

Tardif et al., 1986

Hoage, 1978

mother and

father

mother (for Symington, 1987

A. paniscus)

mother and

allomothers

Carol Mitchell, pers. comm.

primarily

mother

primarily

mother

in Nicolson, 1987

Dunbar, 1984

Mitani, 1987

Fossey, 1983

Nishida, 1983

${ }^{a}$ References for litter/mother weight ratios are in Leutenegger (1973) and Kleiman (1977). 


\section{Twinning}

Leutenegger $(1973,1979)$ suggested that callitrichid ancestors evolved an increased frequency of twinning as dwarfing occurred, because the heads of their singleton of fspring became too large for easy delivery through the mothers' pelvic canals. He showed that among primates, both neonatal/ maternal body weight ratios and neonatal brain/body size ratios are negative allometric relationships, so that the smaller a primate species the larger the neonates' heads relative to their mothers' pelvic canals. He then noted that in Saimiri, in which females weigh about $0.6-0.7 \mathrm{~kg}$ and the litter/mother weight ratio is 0.14 , deliveries are very difficult and often unsuccessful (from Goss et al., 1968). According to Leutenegger, ancestral callitrichids evolved twinning because this allowed them to produce the same litter weight as they had before, but as two infants with smaller heads instead of one with too large a head.

This argument seems insufficient; it seems that there would have had to be additional benefits to twinning in order to outweigh the high costs of rearing twins. Leutenegger did not explain why ancestral callitrichids did not simply evolve to produce one infant at a time that was small enough to be born easily. The negative allometric relationship of litter/mother weight ratios in primates suggests only that smaller primates are somehow able to produce larger litter weights. Leutenegger's argument implies, conversely, that smaller primates must, for some reason, have larger litter weights, but he does not explain why.

Given that callitrichids' small size allowed them to produce twins, a high predation rate on the young may have been the factor that made twinning beneficial. Infant mortality during the first year for $S$. fuscicollis in Peru's Manu National Park is 30 to $50 \%$ (about $70 \%$ of young survived to 6-12 months of age; Goldizen and Terborgh, 1989). Most of this mortality is probably due to predation occurring soon after the young begin to travel independently; such mortality would not be tied closely to the infants' size or to the parents' ability to raise young. This suggests that a young callitrichid with a twin would not have been twice as likely to fall victim to a predator than would an infant without a twin.

Seasonal breeding could also have helped to make twinning adaptive. Although most callitrichids are able to breed twice per year in captivity (e.g., Gengozian et al., 1978, for S. fuscicollis and S. oedipus), in all tamarin species studied in the wild births showed a nonrandom seasonal distribution, and individual females did not have more than one litter per year on average (reviewed by Goldizen et al., 1988). If callitrichid ancestors were also seasonal breeders, and often lost their single infants to predators, they could not have immediately conceived replacements. Thus, those that had twins 
and lost one infant to a predator would still have had another to invest in that year. However, callitrichid ancestors may not have been seasonal breeders, since some marmoset species are not (e.g., C. humeralifer; Rylands, 1985).

\section{Helping}

In the biological literature, helpers are individuals which provide care for other individuals' young (Skutch, 1935). Helping behavior (also called alloparental behavior) is widespread among birds and mammals; it has been observed in over 222 bird species (Brown, 1987) and 120 mammal species (Riedman, 1982). Helpers are sometimes individuals which are not breeders, though they may be sexually mature; at other times helpers are reproductive and may even have infants of their own while they help raise those of others. The details of helping behavior vary in different species; Table II presents some information on helping in six well-studied species of cooperatively breeding birds.

Allomaternal care has been observed in a number of primate species, including ring-tailed lemurs (Lemur catta), howler monkeys (Alouatta seniculus), gray langurs (Presbytis entellus), black-and-white colobus (Colobus guereza), vervet monkeys (Cercopithecus aethiops), patas monkeys (Erythrocebus patas), Japanese macaques (Macaca fuscata), rhesus macaques (M. mulatta), savanna baboons (Papio cynocephalus), gelada baboons (Theropithecus gelada), gorillas (Gorilla gorilla), and chimpanzees (Pan troglodytes)-reviewed by Riedman, 1982; Nicolson, 1987. Some of these allomothers were nonreproductive females; others were females with young of their own. In primates other than callitrichids, significant helping behavior by nonreproductive males is not very common, while allopaternal care by reproductive males is hard to measure because of the difficulty of assigning paternity in many species.

The helping behavior of young callitrichids can probably be better understood through comparisons with nonprimates instead of primates for several reasons. (1) The helping exhibited by many young tamarins and marmosets is probably substantially more frequent and energetically costly than is the alloparental behavior of most other primates. (2) In callitrichids, young of both sexes seem to give approximately equal amounts of help, as occurs in many cooperatively breeding bird species (Table II), but unlike most other primates. (3) There have been few systematic studies of patterns of helping in primates, while there have been dozens of such studies on birds (Emlen, 1984; Brown, 1987).

To understand why sexually immature individuals serve as helpers we need to ask two questions. (1) How do these helpers gain in inclusive fitness 


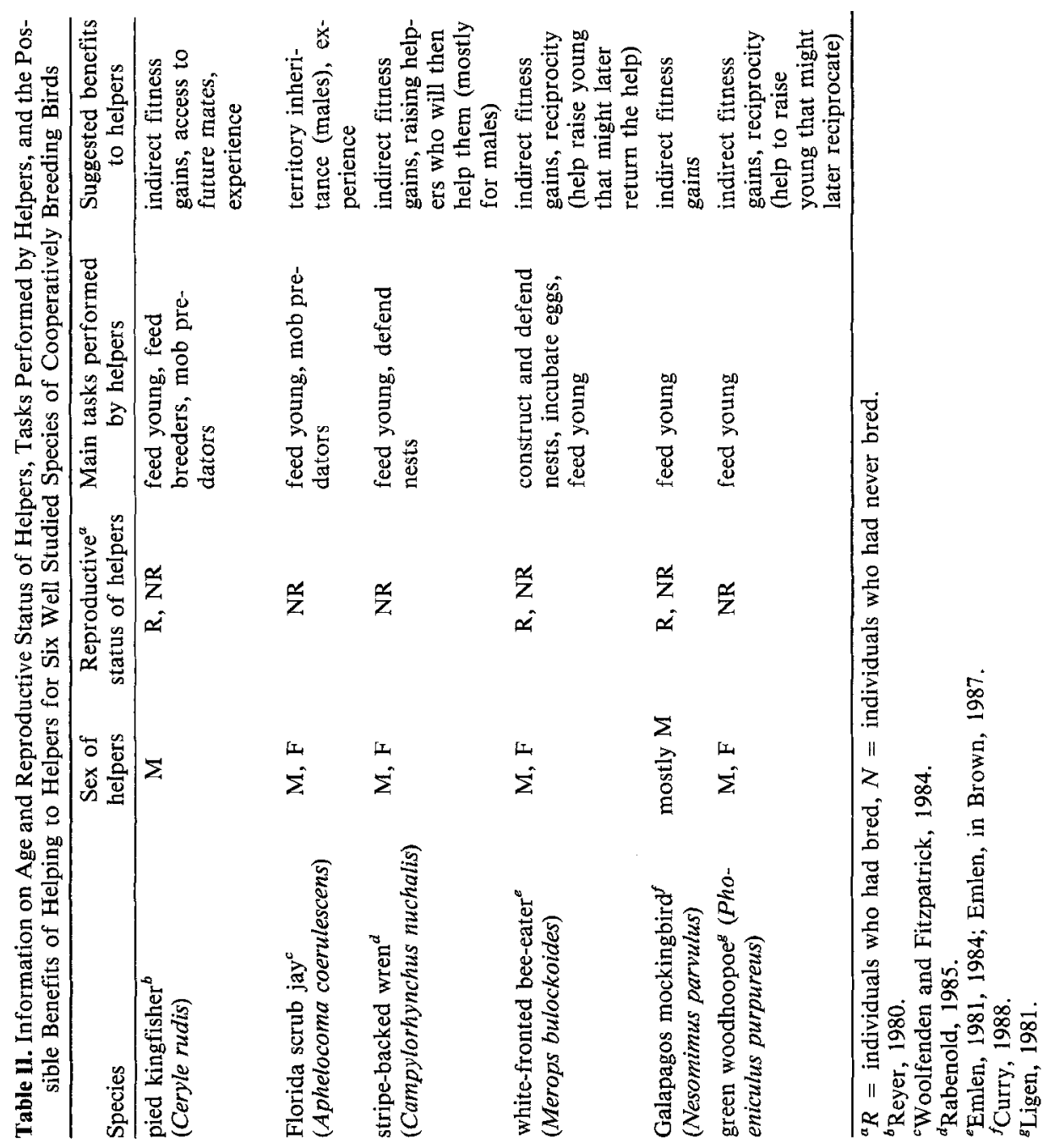


(Hamilton, 1964) from their helping behavior? (2) How do parents gain from being helped? To understand why sexually mature, yet nonreproductive, individuals help, we need to ask two additional questions. (3) Why do these individuals postpone their own breeding? (4) Given that these individuals have postponed breeding, why are they living in a territory (usually their natal territory) with breeding individuals, instead of dispersing in search of a territory and/or mate for themselves?

I will begin with the last two questions. Research on cooperatively breeding birds has suggested a number of reasons why individuals might not breed as soon as they are physiologically capable of reproduction. These hypotheses propose that delayed breeding might be due to (1) severe environmental conditions that reduce the chance of successful breeding (Emlen, 1982), (2) dangers of dispersal, (3) saturation of suitable breeding habitat (Selander, 1964; Stacey, 1979a), (4) lack of potential mates, (5) insufficient foraging skills for successful breeding (Ashmole, 1963; Heinsohn et al., 1988), or (6) inclusive fitness benefits of helping to rear siblings (reviewed in Brown, 1987). The study of wild $S$. fuscicollis in Peru's Manu National Park suggests that dispersal dangers, habitat saturation and inclusive fitness benefits, as well as a shortage of potential helpers, are possible causes of delayed breeding in this species (Goldizen and Terborgh, 1989).

There are various reasons why an individual that delays breeding might benefit from remaining in its natal territory, if permitted to do so (reviewed by Brown, 1987). (1) There may be no vacant habitat into which such individuals can move. (2) Undirected dispersal may be too risky because of the dangers of predation and the difficulty of finding food in unknown areas. Individuals remaining in their natal territories would have access to known food patches and might suffer reduced predation risks because of being in a group. (3) Individuals remaining in their natal groups might eventually be able to breed in that territory. (4) Individuals which remain in their natal territories might be able to increase their inclusive fitness by helping to rear siblings, and increasing those siblings' chances of survival. Wild tamarins often remain in their natal territories for one or more years past the time when they could potentially be breeding on their own (Goldizen and Terborgh, 1989). Unfortunately, there is not enough information on wild callitrichids to evaluate the four possible explanations for delayed dispersal listed above, although all seem to be reasonable for tamarins.

When an individual is in its natal group, how might helping to rear its siblings increase its inclusive fitness? Again, work on cooperatively breeding birds has suggested several possibilities. (1) If helpers increase the survival chances of their siblings, they would increase the indirect fitness component of their own inclusive fitness (e.g., Rabenold, 1985; Curry, 1988). (2) The help that helpers give might be reciprocated in the future (Trivers, 
1971; Axelrod and Hamilton, 1981). (3) Helpers might increase their own future reproductive success by gaining experience with infant care (Gartlan, 1969; Lancaster, 1971). (4) Helping might increase a helper's chances of obtaining a territory or a mate (Woolfenden and Fitzpatrick, 1978, 1984). (5) Helpers might help as a form of payment for being allowed to stay in the safety of their natal territory (Gaston, 1978).

Again, there are too few data on helpers in wild callitrichids to do more than speculate on possible benefits of helping to helpers. (1) Since three or more caretakers seem important for the successful raising of offspring (see below), helpers probably often gain inclusive fitness benefits from increasing the survival of their siblings. (2) We have so far observed one case of possible reciprocity in helping among the S. fuscicollis at Manu; one female, which inherited the breeding position in her natal territory, also inherited potential helpers in the younger siblings that she herself had helped to rear. (3) At least three captive studies have suggested that adult callitrichids are much better at rearing their own young if they had experience carrying their siblings (Epple, 1975, on S. fuscicollis; Hoage, 1978, on L. rosalia; Tardif et al., 1984, on C. jacchus and S. oedipus). However, to know whether callitrichids require the actual experience of carrying young, one would need to compare the reproductive success of first-time breeders that had been allowed to carry younger siblings with the reproductive success of first-time breeders that had watched others carry young but had not been allowed to carry any themselves. This has not yet been done. (4) In two cases at Manu, female $S$. fuscicollis that served as helpers in their natal territories eventually inherited both the territories and their mothers' mates upon the deaths of the mothers (Goldizen, unpubl. observ.).

The last of the questions regarding helping pertains to the benefits to the parents. It has been shown for many cooperatively breeding bird species that pairs with helpers raise more young than pairs without helpers (Florida scrub jays, Aphelocoma coerulescens, Woolfenden and Fitzpatrick, 1984; gray-crowned babblers, Pomatostomus temporalis, Brown et al., 1982; reviewed by Emlen, 1978, pp. 252-253; Brown, 1987, p. 171). In callitrichids too, helpers are almost certainly beneficial. In fact, in S. fuscicollis, it appears that a pair without at least one helper would have a poor chance of raising offspring (see below). However, studies of callitrichids will never involve sample sizes as large as those in studies of birds, and this will make it hard to evaluate the relationship between reproductive success and number of helpers in callitrichids.

\section{Variable Mating Patterns}

The evolution of twinning (which increased the costs of infant care) and of helping by nonreproductive offspring probably set the stage for the 
evolution of flexible mating patterns in some or all callitrichid species. To explain the unusually variable mating patterns of $S$. fuscicollis, Goldizen and Terborgh (1986) and Goldizen (1987b) suggested that lone pairs would have a poor chance of raising offspring, and thus, if a pair did not have older offspring which could serve as helpers, both members of the pair would benefit from mating as a polyandrous trio with another male. Data on the costs of lactation and infant-carrying suggest that lone pairs would not be able to accomplish both of these tasks and still get enough to eat (Goldizen, 1987b). In fact, lone pairs have been very rare in Manu, and none conceived offspring during our study (Goldizen, 1987b). There are still not enough data on the compositions of monogamous and polyandrous groups to test adequately the suggestion that groups without helpers should be polyandrous, while those with helpers should be monogamous.

If the callitrichid species with variable mating patterns have indeed evolved the ability to adjust their mating patterns in response to the number of potential helpers present in their groups, it is not surprising that most captive individuals would show a preference for monogamous pairing. Rearing infants is much less energetically costly in captivity than in the wild, since captive animals do not have to carry their infants long distances, and are provided with more than adequate food supplies. Therefore, captive pairs should not need extra help, and while captive females might still benefit somewhat from mating polyandrously, males presumably would not. By similar reasoning, the costs of infant care probably vary for different species in the wild, or even for different populations of the same species (e.g., because of different daily travel distances), and this might affect the frequencies of polyandrous groups.

The sequence of evolutionary events undergone by saddle-back tamarins may have put males of the species in an awkward situation. I have suggested that male $S$. fuscicollis presented with a high probability of twin infants and no older offspring to serve as helpers, on average, would increase their fitness by being polyandrous rather than monogamous (Goldizen, 1987b). But would not the best solution for these males have been to be mated to monogamous females which had single instead of twin infants? This was perhaps simply not an evolutionary possibility for male tamarins. Any negative effects of twinning on males would have been of far less importance for the evolution of twinning than would its benefits to females. Thus, for male tamarins, a less than ideal mating system may have been the best response to evolution in the other sex.

Cooperative polyandry has not been found to occur regularly in any other species of mammal except for humans (e.g., Goldstein, 1971), but it occurs in some birds: dunnocks (Prunella modularis) (Davies, 1983, 1985; Davies and Lundberg, 1984), Tasmanian native hens (Tribonyx mortierii) (Ridpath, 1972b; Maynard Smith and Ridpath, 1972), acorn woodpeckers (Melanerpes formicivorous) (Stacey, 1979b; Koenig and Mumme, 1987), 
dusky moorhens (Gallinula tenebrosa) (Garnett, 1978, 1980), pukekos (Porphyrio porphyrio) (Craig, 1980a; Jamieson and Craig, 1987), and Galapagos hawks (Buteo galapagoensis) (Faaborg et al., 1980; Faaborg, 1986). The causes of cooperative polyandry appear to be somewhat different in each of these species and in S. fuscicollis. For example, in dunnocks, males usually would have higher inclusive fitness by mating monogamously or polygynously, but sometimes they cannot prevent other males from copulating with their females; thus, they are forced into cooperative polyandry (Davies and Lundberg, 1984; Davies, 1986). In Tasmanian native hens, a male-biased sex ratio and the fact that polyandrous males are usually closely related may make polyandry beneficial to at least some males (Maynard Smith and Ridpath, 1972).

In many of these cooperatively polyandrous species, trios successfully raise more offspring, on average, than pairs do (Ridpath, 1982b, for Tasmanian native hens; Koenig et al., 1983, for acorn woodpeckers; Davies, 1986, for dunnocks; Faaborg, 1986, for Galapagos hawks; but see Craig, 1980b, for opposite finding for pukekos). However, the need for extra help with offspring care has probably not been as important in the evolution of cooperative polyandry in these species as in $S$. fuscicollis.

Despite the differences between these birds and callitrichids, an understanding of the dynamics of polyandry in birds can help us to understand better the evolution of polyandry in callitrichids. For example, males in species that exhibit facultative cooperative polyandry face two problems. First, should they only accept polyandrous status without a struggle if their inclusive fitness is likely to be increased by mating polyandrously? Secondly, should males in polyandrous groups only care for the young produced by their females if they have at least a good chance of having fathered those young?

Tasmanian native hens and dunnocks shed some light on the first question. Dominant male dunnocks do not seem to benefit from being polyandrous (Davies and Lundberg, 1984; Davies, 1986), and they try hard to keep other males from mating with their females (Davies, 1985). On the other hand, Tasmanian native hen males appear to benefit often from polyandry (Maynard Smith and Ridpath, 1972) and aggression among adult group members is very rare (Ridpath, 1972a). It has not been shown that males of a single species can show these two opposite types of reactions, but it seems a reasonable possibility. One pair of polyandrous male $S$. fuscicollis was surprisingly unaggressive to each other (Goldizen, 1989); perhaps this was because both of them were benefiting from being polyandrous.

The relationship between probability of paternity and male parental care has been investigated in dunnocks and pukekos. In dunnock trios, in 
which the subordinate males were prevented from mating by the dominant males, they did not help to feed the young (Davies, 1986). In pukekos, the results were less clear. In groups with multiple males, those males with the highest probability of paternity performed less incubation of eggs but spent more time in chick care than did the other males (Craig and Jamieson, 1985).

\section{CONCLUSIONS}

Saddle-back tamarins apparently evolved the ability to vary their mating and infant care behaviors according to the particular demographic and ecological conditions in which they find themselves. However, at least in Peru's Manu National Park, their decisions about mating patterns appear to be more directly affected by demographic factors, especially the number of older offspring in the group, than by ecological conditions. This is quite different from dunnocks, in which males whose females have large territories are usually polyandrous, while the mates of females with small territories are more often monogamous (Davies and Lundberg, 1984). Of course, ecological factors affect tamarin mating patterns indirectly by determining the energetic costs of infant care (e.g., through food availability and daily travel lengths).

In fact, while mating patterns within tamarin populations may be determined by demographic factors, differences between the mating patterns of different populations or different callitrichid species may be ecologically determined. Although little is known about the mating patterns of most species, there are indications that major differences in social systems exist between species. For example, group compositions seem more fluid in some species (S. oedipus, Dawson, 1978; Neyman, 1978) than others (S. fuscicollis, Goldizen, 1988; Goldizen and Terborgh, 1989). If the mating patterns of callitrichids turn out to vary between species we will have an excellent opportunity to understand how ecological differences affect social structure, since they are very close phylogenetically but vary substantially in their feeding and ranging patterns (Sussman and Kinzey, 1984; Goldizen, 1987a).

\section{ACKNOWLEDGMENTS}

I thank M. McFarland Symington, D. Watts, and two reviewers for comments on an earlier version of the manuscript, and I. DeVore and K. Strier for the opportunity to participate in the symposium from which this paper developed. 


\section{REFERENCES}

Ashmole, P. (1963). The regulation of numbers of tropical oceanic birds. Ibis 103: 458-473. Axelrod, R., and Hamilton, W. D. (1981). The evolution of cooperation. Science 211: 1390-1396. Bearder, S. K. (1987). Lorises, bushbabies, and tarsiers: Diverse societies in solitary foragers. In Smuts, B. B., Cheney, D. L., Seyfarth, R. M., Wrangham, R. W., and Struhsaker, T. T. (eds.), Primate Societies, Univ. of Chicago Press, Chicago, pp. 11-24.

Box, H. O. (1975). A social developmental study of young monkeys (Callithrix jacchus) within a captive family group. Primates 16: 419-435.

Brown, J. L. (1987). Helping and Communal Breeding in Birds: Ecology and Evolution, Princeton Univ. Press, Princeton.

Brown, J. L., Brown, E. R., Brown, S. D., and Dow, D. D. (1982). Helpers: Effects of experimental removal on reproductive success. Science 215: 421-422.

Brown, K., and Mack, D. S. (1978). Food sharing among captive Leontopithecus rosalia. Folia Primatol. 29: 268-290.

Cebul, M. S., and Epple, G. (1984). Father-offspring relationships in laboratory families of saddle-back tamarins (Saguinus fuscicollis). In Taub, D. M. (ed.), Primate Paternalism, van Nostrand Reinhold, New York, pp. 1-19.

Chivers, D. J. (1974). The siamang in Malaya. In Contributions to Primatology, Vol. 4, S. Karger, Basel.

Coates, A., and Poole, T. B. (1983). The behavior of the callitrichid monkey, Saguinus labiatus labiatus, in the laboratory. Int. J. Primatol. 4: 339-371.

Craig, J. L. (1980a). Pair and group breeding behaviour of a communal gallinule, the pukeko, Porphyrio p. melanotus. Anim. Behav. 28: 593-603.

Craig, J. L. (1980b). Breeding success of a communal gallinule. Behav. Ecol. Sociobiol. 6: 289-295.

Craig, J. L., and Jamieson, I. G. (1985). The relationships between presumed gamete contribution and parental investment in a communally breeding bird. Behav. Ecol. Sociobiol. 17: 207-211.

Curry, R. L. (1988). Influence of kinship on helping behavior in Galapagos mockingbirds. Behav. Ecol. Sociobiol. 22: 141-152.

Davies, N. B. (1983). Polyandry, cloaca pecking, and sperm competition in dunnocks. Nature, Lond., 302: 334-336.

Davies, N. B. (1985). Cooperation and conflict among dunnocks, Prunella modularis, in a variable mating system. Anim. Behav. 33: 628-648.

Davies, N. B. (1986). Reproductive success of dunnocks, Prunella modularis, in a variable mating system. I. Factors influencing provisioning rate, nestling weight and fledging success. J. Anim. Ecol. 55: 123-138.

Davies, N. B., and Lundberg, A. (1984). Food distribution and a variable mating system in the dunnock, Prunella modularis. J. Anim. Ecol. 53: 895-912.

Dawson, G. A. (1978). Composition and stability of social groups of the tamarin, Saguinus oedipus geoffroyi, in Panama: Ecological and behavioral implications. In Kleiman, D. G. (ed.), The Biology and Conservation of the Callitrichidae, Smithsonian Institution Press, Washington, D.C., pp. 23-37.

Dietz, J. M., and Kleiman, D. G. (1986). Reproductive parameters in groups of free-living golden lion tamarins. Primate Report 14: 77.

Dunbar, R. I. M. (1984). Reproductive Decisions: An Economic Analysis of Gelada Baboon Social Strategies, Princeton Univ. Press, Princeton.

Eisenberg, J. F., Muckenhirn, N. A., and Rudran, R. (1972). The relation between ecology and social structure in primates. Science 176: 863-874.

Emlen, S. T. (1978). The evolution of cooperative breeding in birds. In Krebs. J. R., and Davies, N. B. (eds.), Behavioural Ecology: An Evolutionary Approach, Sinauer Associates, Sunderland, Massachusetts, pp. 245-281.

Emlen, S. T. (1981). Altruism, kinship, and reciprocity in the white-fronted bee-eater. In Alexander, R. D., and Tinkle, D. W. (eds.), Natural Selection and Social Behavior: Recent Research and New Theory, Chiron Press, New York, pp. 217-230. 
Emlen, S. T. (1982). The evolution of helping. I. An ecological constraints model. Am. Nat. 119: $29-39$.

Emlen, S. T. (1984). Cooperative breeding in birds and mammals. In Krebs, J. R., and Davies, N. B. (eds.), Behavioural Ecology, Sinauer Associates, Sunderland, Massachusetts, pp. 305-339.

Epple, G. (1972). Social behavior of laboratory groups of $S$. fuscicollis. In Bridgewater, P. D. (ed.), Saving the Lion Marmoset, Proceedings of the WAPT Golden Lion Marmoset Conference, WAPT, Oglebay Park, Wheeling, West Virginia, pp. 50-58.

Epple, G. (1975). Parental behavior in Saguinus fuscicollis spp. (Callitrichidae). Folia Primatol. 24: 221-238.

Epple, G. (1978). Reproductive and social behavior of marmosets with special reference to captive breeding. Prim. Med. 10: 50-62.

Faaborg, J. (1986). Reproductive success and survivorship of the Galapagos hawk Buteo galapagoensis: Potential costs and benefits of cooperative polyandry. Ibis 128: 337-347.

Faaborg, J., and Patterson, C. B. (1981). The characteristics and occurrence of cooperative polyandry. Ibis 123: 477-484.

Faaborg, J., de Vries, T. J., Patterson, C. B., and Griffin, C. R. (1980). Preliminary observations on the occurrence and evolution of polyandry in the Galapagos hawk (Buteo galapagoensis). Auk 97: 581-590.

Ford, S. M. (1980). Callitrichids as phyletic dwarfs, and the place of Callitrichidae in Platyrrhini. Primates 21: 31-43.

Fossey, D. (1983). Gorillas in the Mist, Houghton Mifflin Company, Boston.

Garber, P. A. (1986). Social organization and patterns of infant transport in Saguinus mystax in Amazonian Peru. Primate Report 14: 78.

Garber, P. A., Moya, L., and Malaga, C. (1984). A preliminary field study of the moustached tamarin monkey (Saguinus mystax) in northeastern Peru: Questions concerned with the evolution of a communal breeding system. Folia Primatol. 42: 17-32.

Garnett, S. T. (1978). The behaviour patterns of the dusky moorhen, Gallinula tenebrosa Gould (Aves: Rallidae), Aust. Wildl. Res. 5: 363-384.

Garnett, S. T. (1980). The social organization of the dusky moorhen, Gallinula tenebrosa Gould (Aves: Rallidae). Aust. Wildl. Res. 7: 103-112.

Gartlan, S. (1969). Sexual and maternal behavior of the vervet monkey (Cercopithecus aethiops). J. Reprod. Fertil. (Suppl.) 6: 137-150.

Gaston, A. J. (1978). The evolution of group territorial behavior and cooperative breeding. Am. Nat. 112: 1091-1100.

Gengozian, N., Batson, J. S., and Smith, T. A. (1978). Breeding of marmosets in a colony environment. Prim. Med. 10: 71-78.

Goldizen, A. W. (1987a). Tamarins and marmosets: Communal care of offspring. In Smuts, B. B., Cheney, D. L., Seyfarth, R. M., Wrangham, R. W., and Struhsaker, T. T. (eds.), Primate Societies, University of Chicago Press, Chicago, pp. 34-43.

Goldizen, A. W. (1987b). Facultative polyandry and the role of infant-carrying in wild saddleback tamarins (Saguinus fuscicollis). Behav. Ecol. Sociobiol. 20: 99-109.

Goldizen, A. W. (1988). Tamarin and marmoset mating systems: Unusual flexibility. Trends Ecol. Evol. 3: 36-40.

Goldizen, A. W. (1989). Social relationships in a cooperatively polyandrous group of tamarins (Saguinus fuscicollis). Behav. Ecol. Sociobiol. 24: 79-89.

Goldizen, A. W., and Terborgh, J. (1986). Cooperative polyandry and helping behavior in saddleback tamarins (Saguinus fuscicollis). In Else, J. G., and Lee, P. (eds.), Primate Ecology and Conservation, Proc. of the 10th Congress of the International Primatological Society, Vol. 2, Cambridge Univ. Press, Cambridge, pp. 191-198.

Goldizen, A. W., and Terborgh, J. (1989). Demography and dispersal patterns of a tamarin population: Possible causes of delayed breeding. Am. Nat. 134: 208-224.

Goldizen, A. W., Terborgh, J., Cornejo, F., Porras, D. T., and Evans, R. (1988). Seasonal food shortage, weight loss, and the timing of births in saddle-back tamarins (Saguinus fuscicollis). J. Anim. Ecol. 57: 893-901.

Goldstein, M. C. (1971). Stratification, polyandry, and family structure in Central Tibet. Southwest J. Anthropol. 27: 64-74. 
Goss, C. M., Popejoy, L. T., II, Fusiler, J. L., and Smith, T. M. (1968). Observations on the relationships between embryological development, time of conception, and gestation. In Rosenblum, and Cooper (eds.), The Squirrel Monkey, Academic Press, New York, pp. 171:191.

Hamilton, W. D. (1964). The genetical evolution of social behavior. I, II. J. Theor. Biol. 7: 1-52.

Heinsohn, R. G., Cockburn, A., and Cunningham, R. B. (1988). Foraging, delayed maturation, and advantages of cooperative breeding in white-winged choughs, Corcorax melanorhamphos. Ethology 77: 177-186.

Hershkovitz, P. (1977). Living New World Monkeys (Platyrrhini), Vol. 1, University of Chicago Press, Chicago.

Hoage, R. J. (1978). Parental care in Leontopithecus rosalia rosalia: Sex and age differences in carrying behavior and the role of prior experience. In Kleiman, D. G. (ed.), The Biology and Conservation of the Callitrichidae, Smithsonian Institution Press, Washington, D.C., pp. 293-305.

Hubrecht, R. C. (1984). Field observations on group size and composition of the common marmoset (Callithrix jacchus jacchus), at Tapacura, Brazil. Primates 25: 13-21.

Hubrecht, R. C. (1985). Home-range size and use and territorial behavior in the common marmoset, Callithrix jacchus jacchus, at the Tapacura Field Station, Recife, Brazil, Int. J. Primatol. 6: 533-550.

Ingram, J. C. (1977). Interactions between parents and infants, and the development of independence in the common marmoset (Callithrix jacchus). Anim. Behav. 25: 811-827.

Izawa, K. (1978). A field study of the ecology and behavior of the black-mantle tamarin (Saguinus nigricollis). Primates 19: 241-274.

Jamieson, I. G., and Craig, J. L. (1987). Dominance and mating in a communal polygynandrous bird: Cooperation or indifference towards mating competitors? Ethology 75: 317-327.

Kirkwood, J. K., and Underwood, S. J. (1984). Energy requirements of captive cotton-top tamarins (Saguinus oedipus oedipus). Folia Primatol. 42: 180-187.

Kleiman, D. G. (1977). Monogamy in mammals. Q. Rev. Biol. 52: 39-69.

Koenig, W. D., and Mumme, R. L. (1987). Population Ecology of the Cooperatively Breeding Acorn Woodpecker, Princeton Univ. Press, Princeton.

Koenig, W. E., Mumme, R. L., and Pitelka, F. A. (1983). Female roles in cooperatively breeding acorn woodpeckers. In Wasser, S. K. (ed.), Social Behavior of Female Vertebrates, Academic Press, New York, pp. 235-261.

Lancaster, J. B. (1971). Play mothering: The relationships between juvenile females and young infants among free-ranging vervet monkeys (Cercopithecus aethiops). Folia Primatol. 15: $161-182$.

Leutenegger, W. (1973). Maternal-fetal weight relationships in primates. Folia Primatol. 20: 280-293.

Leutenegger, W. (1979). Evolution of litter size in primates. Am. Nat. 114: 525-531.

Leutenegger, W. (1980). Monogamy in callitrichids: A consequence of phyletic dwarfism? Int. J. Primatol. 1: 95-98.

Ligon, J. D. (1981). Demographic patterns and communal breeding in the green woodhoopoe, Phoeniculus purpureus. In Alexander, R. D., and Tinkle, D. W. (eds.), Natural Selection and Social Behavior: Recent Research and New Theory, Chiron Press, New York, pp. 231-243.

Maynard Smith, J., and Ridpath, M. G. (1972). Wife sharing in the Tasmanian native hen (Tribonyx mortierii): A case of kinship selection? Am. Nat. 106: 447-452.

McGrew, W. C. (1988). Parental division of infant caretaking varies with family composition in cotton-top tamarins. Anim. Behav. 36: 285-310.

Neyman, P. F. (1978). Aspects of the ecology and social organization of free-ranging cottontop tamarins (Saguinus oedipus) and the conservation status of the species. In Kleiman, D. G. (ed.), The Biology and Conservation of the Callitrichidae, Smithsonian Institution Press, Washington, D.C., pp. 39-71.

Nicolson, N. A. (1987). Infants, mothers, and other females. In Smuts, B. B., Cheney, D. L., Seyfarth, R. M., Wrangham, R. W., and Struhsaker, T. T. (eds.), Primates Societies, Univ. of Chicago Press, Chicago, pp. 330-342. 
Nishida, T. (1983). Alloparental behavior in wild chimpanzees of the Mahale Mountains, Tanzania. Folia Primatol. 41: 1-33.

Rabenold, K. N. (1985). Cooperation in breeding by nonreproductive wrens: Kinship, reciprocity, and demography. Behav. Ecol. Sociobiol. 17: 1-17.

Reyer, H.-U. (1980). Flexible helper structure as an ecological adaptation in the pied kingfisher (Ceryle rudis rudis L.). Behav. Ecol. Sociobiol. 6: 219-227.

Richard, A. F. (1987). Malagasy prosimians: Female dominance. In Smuts, B. B., Cheney, D. L., Seyfarth, R. M., Wrangham, R. W., and Struhsaker, T. T. (eds.), Primate Societies, Univ. of Chicago Press, Chicago, pp. 25-33.

Ridpath, M. G. (1972a). The Tasmanian native hen, Tribonyx mortierii. I. Patterns of behaviour. CSIRO Wildlife Res. 17: 1-51.

Ridpath, M. G. (1977b). The Tasmanian native hen, Tribonyx mortierii. II. The individual, the group, and the population. CSIRO Wildlife Res. 17: 53-90.

Riedman, J. L. (1982). The evolution of alloparental care and adoption in mammals and birds. Quart. Rev. Biol. 57: 405-435.

Rodman, P. S., and Mitani, J. C. (1987). Orangutans: Sexual dimorphism in a solitary species. In Smuts, B. B., Cheney, D. L., Seyfarth, R. M., Wrangham, R. W., and Struhsaker, T. T. (eds.), Primate Societies, Univ, of Chicago Press, Chicago, pp. 146-154.

Rylands, A. B. (1985). Infant-carrying in a wild marmoset group, Callithrix humeralifer: Evidence for a polyandrous mating system. A Primatologia No Brazil 2: 131-144.

Selander, R. K. (1964). Speciation in wrens of the genus Campylorhynchus. Univ. Calif. Publ. Zool. 74: 257-273.

Skutch, A. F. (1935). Helpers at the nest. $A u k$ 52: 257-273.

Snowdon, C. T., and Soini, P. (In press). The tamarins: Genus Saguinus. In Mittermeier, R. A., and Coimbra-Filho, A. F. (eds.), Ecology and Behavior of Neotropical Primates, Academia Brasileira de Ciencias, Rio de Janeiro.

Soini, P. (1987). Sociosexual behavior of a free-ranging Cebuella pygmaea (Callitrichidae, Platyrrhini) troop during postpartum estrus of its reproductive female. Am. J. Primatol. 13: 223-230.

Stacey, P. B. (1979a). Habitat saturation and communal breeding in the acorn woodpecker. Anim. Behav. 27: 1153-1166.

Stacey, P. B. (1979b). Kinship, promiscuity and communal breeding in the acorn woodpecker. Behav. Ecol. Sociobiol. 6: 53-66.

Sussman, R. W., and Kinzey, W. G. (1984). The ecological role of the Callitrichidae. Am. J. Phys. Anthrop. 64: 419-449.

Symington, M. M. (1987). Sex ratio and maternal rank in wild spider monkeys: When daughters disperse. Behav. Ecol. Sociobiol. 20: 421-425.

Tardif, S. D., Carson, R. L., and Gangaware, B. L. (1986). Comparison of infant care in family groups of the common marmoset (Callithrix jacchus) and the cotton-top tamarin (Saguinus oedipus). Am. J. Primatol. 11: 103-110.

Tardif, S. D., Richter, C. B., and Carson, R. L. (1984). Effects of sibling-rearing experience on future reproductive success in two species of Callitrichidae. Am. J. Primatol. 6: 377-380.

Terborgh, J., and Goldizen, A. W. (1985). On the mating system of the cooperatively breeding saddle-back tamarin (Saguinus fuscicollis). Behav. Ecol. Sociobiol. 16: 293-299.

Trivers, R. L. (1971). The evolution of reciprocal altruism. Q. Rev. Biol. 46: 35-57.

Vogt, J. L., Carlson, H., and Menzel, E. (1978). Social behavior of a marmoset (Saguinus fuscicollis) group. I: Parental care and infant development. Primates 19: 715-726.

Wolfe, L. G., Deinhardt, F., Ogden, J. D., Adams, J. R., and Fisher, L. E. (1975). Reproduction of wild-caught and laboratory-born marmoset species used in biomedical research (Saguinus sp., Callithrix jacchus). Lab. Anim. Sci. 25: 802-813.

Woolfenden, G. E., and Fitzpatrick, J. W. (1978). The inheritance of territory in group-breeding birds. Bioscience 28: 104-108.

Woolfenden, G. E., and Fitzpatrick, J. W. (1984). The Florida Scrub Jay: Demography of a Cooperative-Breeding Bird, Princeton Univ. Press, Princeton.

Wright, P. C. (1984). Biparental care in Aotus trivirgatus and Callicebus moloch. In Small, M. F. (ed.), Female Primates: Studies by Women Primatologists, Alan R. Liss, New York, pp. 59-75. 